\title{
Correspondence
}

\section{Accuracy of routine clinical test weighing}

\section{Sir,}

I congratulate Whitfield et al. ${ }^{1}$ on their thorough analysis of the accuracy of test feeding in the clinical situation, but disagree with their statement that 'test weighing with clinical baby scales is an unreliable and inaccurate indication of feed intake .... They used Salter 'Trent' scales; these are spring balances with the scale marked in $10 \mathrm{~g}$ divisions and variations of up to $10 \mathrm{~g}$ due to parallax must be expected; therefore this type of balance is unsuitable for this purpose.

Beam-balances, for example those manufactured by Ohio Limited and Stevens and Son, are popular choices for clinical use. These avoid such errors and their accuracy can be enhanced by adding 1 to $5 \mathrm{~g}$ weights to the tray.

When using such a system Rahilly ${ }^{2}$ reported a correlation coefficient between the volume of milk given and the consequent weight gain in 17 babies of 0.998 . The measurements were carefully made by a nurse without special training. Many highly trained nurses are excellent cooks and I cannot believe that 'the pressures of modern technology' have impaired their ability to weigh accurately if given the appropriate equipment.

Test weighing can be useful during the establishment of breast feeding and I think it would be wrong to allow its 'general' dismissal to pass without comment.

\section{References}

1 Whitfield M F, Kay R, Stevens S. Validity of routine clinical test weighing as a measure of the intake of breast-fed infants. Arch Dis Child 1981 ; 56: 919-21.

2 Rahilly P M. Effects of sleep state and feeding on cranial blood flow of the human neonate. Arch Dis Child 1980; 55: 265-70.

J K STOTHERS Joint Academic Department of Child Health,

London Hospital Medical College, Turner Street, London E1 $2 A D$

Dr Whitfield comments:

I must stress that the purpose of our study was to make an assessment of the magnitude of the errors likely to occur in routine clinical test weighing, to assist paediatricians in the interpretation of test weighing results presented to them. The study was conducted under clinical 'field' conditions using the type of baby scales routinely available in our hospital, several observers, and several sets of scales. Apart from periodic maintenance and calibration carried out by the hospital for clinical reasons, no additional check on the accuracy of individual scales was made.
Under these conditions we found that test weighing gave an 'unreliable indication of feed intake in breastfed infants'. A better result was obtained by Culley $\boldsymbol{e} t$ al. ${ }^{1}$, although considerable scatter was evident even when observer variability was excluded. The use of a beam balance would provide greater accuracy with the motionless infant; the same degree of accuracy should not be expected when weighing a restless, hungry infant.

The contributions to the total error made by movement of the baby, observer error, and scale inaccuracies, can be minimised by the use of an electronic balance which takes a series of measurements in quick succession. ${ }^{2}$

In the neonatal unit, the ability to measure an infant's weight precisely is important, not only to minimise inaccuracies in test weighing, but also to ascertain adequate weight growth. Acquisition of at least one set of highly accurate scales for this purpose should be considered a budgetary priority.

\section{References}

1 Culley P, Milan P, Roginski C, Waterhouse J, Wood B. Are breast-fed babies still getting a raw deal in hospital? Br Med J 1979; ii: 891-3.

2 Lucas A, Lucas P J, Baum J D. Pattern of milk flow in breast-fed infants. Lancet 1979 ; ii : 57-8.

Sir,

Whitfield et al. concluded that the use of test weighing to measure milk intake in special care babies gives results that are not only inaccurate but also biased, particularly at the extremes. The charge of inaccuracy is true because the usual weighing scales are difficult to read to better than $20 \mathrm{~g}$. For babies with only a small intake per feed this uncertainty is sufficient to affect the measurement appreciably. For older or more healthy babies, where the milk volume per feed is greater, the measurement error is less important. In either case the accuracy can be greatly improved by weighing with an electronic balance which records the baby's weight to within $1 \mathrm{~g}$.

The suggestion that test weighing gives a biased result is more serious. They looked at the regression of feed weight (or FW) on test weight (TW), where FW is the accurately known change in weight of the bottle over the feed, and TW is the observed test weight. This

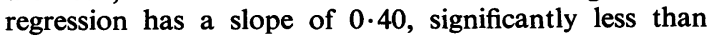
$1(P<0 \cdot 001)$. In general it is unwise to compare two methods of measurement using the regression of one on the other, as neither $Y$ regressed on $X$ nor $X$ on $Y$ gives the correct answer. However, in the present case where FW is measured virtually without error, it is correct to use regression, but with $\mathrm{FW}$ as the independent variable. The regression of TW on FW gives a slope of 0.78 with standard error 0.12 , which is insignificantly different from $1(t=1 \cdot 81, \mathrm{P}>0 \cdot 05)$. Thus the suggestion of bias 
is unfounded and, on average, test weighing gives a result insignificantly different from the true value.

The fact that the slope is rather shallow, although not significant, is of interest; however, it may well be related to the poor accuracy of the scales used. A repeat of the study using an electronic balance ought to lead to a slope appreciably nearer unity.

T J COLE

Dunn Nutritional Laboratory, Milton Road, Cambridge CB4 1 XJ

Dr Whitfield and co-workers comment:

It is clear that the accuracy of the weighing procedure could be considerably improved by using an electronic balance to record baby weight. However, as mentioned on page 920 of the paper the purpose of the study was to investigate 'routine test weighing in the clinical context, rather than as an optimal research procedure'.

The regression analysis undertaken considered the prediction of 'exact' FW from measurement on TW. Information on FW was required given an observed TW; this was the appropriate direction of the regression equation from a practical standpoint. It was not necessary that the independent variable be measured without error when the analysis was to be considered as predicting a measurement $Y$ conditional on the $X$ as observed. Conclusions were therefore based on the regression of FW on TW and the regression of TW on FW was not considered relevant.

\section{Timing of neonatal cerebroventricular haemorrhage with ultrasound}

Sir,

De Crespigny et al. ${ }^{1}$ described the timing of neonatal periventricular haemorrhage using real time ultrasound scanning. Their results demonstrated periventricular haemorrhage within 6 hours of birth in $71 \%$ of 34 infants. These conflict with our results and with those of Levene et al. $^{2}$ and Hope et al. ${ }^{3}$

During the last year we have performed daily ultrasound scans on 290 infants in our unit using an ATL real time $850 \mathrm{~A}$ scanner with $5 \mathrm{MHz}$ transducers. One hundred and eighty-one infants were less than $1500 \mathrm{~g}$ birthweight. Initial scans were performed within 2 hours of birth in inborn infants, and immediately after transfer if born elsewhere in the region. Periventricular haemorrhage occurred in 97 , of which 90 could be timed to within a 12-hour period; 80 of these occurred in infants of very low birthweight. Seventeen haemorrhages began before 12 hours after birth, and 13 between 12 and 24 hours. A further 28 occurred between 24 and 48 hours, and 32 after 48 hours. Of 36 outborn infants who bled, haemorrhage occurred after transfer in 30 . These figures agree generally with those of Levene et al. ${ }^{2}$

Often a preceding precipitating event could be linked temporarily to the development of periventricular
Table Precipitating factors observed to precede periventricular haemorrhage in 90 infants

\begin{tabular}{ll}
\hline Hypercapnia/acidosis & 22 \\
Preterminal event (multifactorial) & 16 \\
Pneumothorax & 14 \\
ETT problem & 12 \\
Birth trauma/asphyxia & $12^{*}$ \\
No observed cause & 12 \\
\hline
\end{tabular}

*3 not transferred_until $>12$ hours old.

haemorrhage (Table). Birth itself could be directly linked to periventricular haemorrhage in the first 12 hours in only 9 infants. Delivery was unmonitored or non-vertex in 7 of them. The other haemorrhages occurring in the first 12 hours were multifactorial preterminal events.

Timing of haemorrhage related to increasing birthweight and maturity in our infants. The mean ( \pm SD) birthweight of infants bleeding before 12 hours was $0.91 \pm 0.23 \mathrm{~kg}$, mean gestation $27 \frac{1}{2}$ weeks. In contrast infants bleeding after 48 hours were larger and more mature $\left(1.25 \pm 0.4 \mathrm{~kg}\right.$, mean gestation $29 \frac{1}{2}$ weeks).

In 12 of 38 infants sustaining a large (Papile's grade $\left.3-4^{4}\right)$ haemorrhage, extension was observed at least 24 hours after the initial bleed. Nine of these infants died, reflecting their underlying severe illness.

We cannot explain the differences in the British results compared with those of de Crespigny but perhaps there were differences in the populations. Perhaps celestial orientation has previously unrecognised effects?

\section{References}

1 De Crespigny L Ch, Mackay R, Murton L J, Roy R N D, Robinson $\mathbf{P} \mathbf{H}$. Timing of neonatal cerebroventricular haemorrhage with ultrasound. Arch Dis Child 1982; 57: 231-3.

2 Levene M I, Wigglesworth J S, Dubowitz V. Cerebral structure and intraventricular haemorrhage in the neonate: a real-time ultrasound study. Arch Dis Child 1981; 56: 416-24.

3 Hope P L, Thorburn R J, Stewart A L, Reynolds E O R. Letter: Prevention of intraventricular haemorrhage by phenobarbitone. Lancet 1981; ii: 527.

4 Papile L A, Burstein J, Burstein R, Koffler H. Incidence and evolution of subependymal and intraventricular hemorrhage; a study of infants with birth weight less than $1500 \mathrm{gm}$. J Pediatr 1978; 92 : 529-34.

M E I MORGAN AND R W I COOKE Liverpool Maternity Hospital, Oxford Street, Liverpool L7 $7 B N$

\section{Munchausen syndrome by proxy and pseudo-epilepsy}

Sir,

Since writing the article published earlier this year ${ }^{1}$ many more cases have been uncovered in which mothers have 